\section{Evolution of Godoy \& Godoy manual lymph drainage. Technique with linear movements}

\section{José Maria Pereira de Godoy, ${ }^{1}$} Ana Carolina Pereira de Godoy, ${ }^{2}$ Maria de Fatima Guerreiro Godoy ${ }^{1-3}$

${ }^{1}$ Department of Cardiology and Cardiovascular Surgery, Medicine School - FAMERP, research CNPq (National Council for Research and Development), São José do Rio Preto; ${ }^{2}$ Department of Pediatric, Santa Casa de São Paulo - Group Research Godoy Clinic, São Paulo; ${ }^{3}$ Occupational Therapist, São José do Rio Preto, Brazil

\begin{abstract}
Manual lymph drainage has become the mainstay in the treatment of lymphedema for decades now. Five evolving variants have been described by Godoy \& Godoy over the years: i) manual lymph drainage using rollers; ii) self-applied manual lymph drainage using rollers; iii) manual lymph drainage using the hands (manual lymphatic therapy); iv) mechanical lymphatic therapy using the RAGodoy ${ }^{\circledR}$ device; and v) lymphatic therapy using cervical stimulation in general lymphatic treatment. After breast cancer treatment using adapted technique with intermittent compression therapy. Lymphoscintigraphy, volumetry and bioimpedance were employed to analyze such treatment techniques applied to the upper
\end{abstract}

and lower extremities. These treatment and evaluation topics are described in this brief report.

\section{Brief Report}

A technique of manual lymph drainage is a light massage therapy introduced by Taylor Still in the late $1800 \mathrm{~s}^{1}$ and first used in the clinical practice in 1936 with the publication by the Vodder method in Paris. This publication recommended hand movements in semicircles based on the circular movements of massage. ${ }^{2}$ This technique, known as manual lymph drainage, became the mainstay in the treatment of lymphedema over the years. Thus it is one of the most important contributions to lymphedema treatment and to many aesthetic procedures.

In 1999 Godoy \& Godoy published a new concept of manual lymph drainage in which they advocate a linear motion along the path of lymphatic vessels towards the corresponding lymph nodes. ${ }^{3,4}$ The main change compared to previously used lymph drainage techniques is the type of movement. In this new method, compression of vessels initially used rollers (Figure 1), but this was eventually changed to hand pressure (Figure 2). The pressure should remain constant along the entire route of the vessel. ${ }^{5}$ The changes in limb volume resulting from the use of this device have been evaluated by lymphoscintigraphy, ${ }^{6-8}$ volumetry ${ }^{9}$ and bioimpedance. ${ }^{10}$

Over the years the Godoy \& Godoy technique has evolved and several books and articles evaluating the therapeutic
Correspondence: José Maria Pereira de Godoy, Avenida Constituição, 1306, São Jose do Rio Preto (SP), CEP: 15025-120, Brazil.

E-mail: godoyjmp@gmail.com

Key words: Lymphedema; manual lymphatic drainage; treatment.

Contributions: the authors contributed equally.

Conflict of interests: the authors declare no potential conflict of interests.

Received for publication: 16 October 2017. Revision received: 12 October 2017.

Accepted for publication: 19 October 2017.

This work is licensed under a Creative Commons Attribution NonCommercial 4.0 License (CC BY-NC 4.0).

(C) Copyright J.M.Pereira de Godoy et al., 2017 Licensee PAGEPress, Italy

Clinics and Practice 2017; 7:1006

doi:10.4081/cp.2017.1006

results have been described. ${ }^{3,4,11-15}$ The first descriptions used rollers for manual lymph drainage with the technique evolving to self-applied manual lymph drainage using rollers (Figures 3 and 4). 3,4,14 The rollers were abandoned after some time due to the difficulty of standardizing the type of material used to manufacture the rollers. Thus, the technique has undergone changes, while maintaining its principle of linear movements in the direction of the lymph nodes.

In vitro, in vivo and clinical studies have been developed to demonstrate the scientific basis of these movements in the

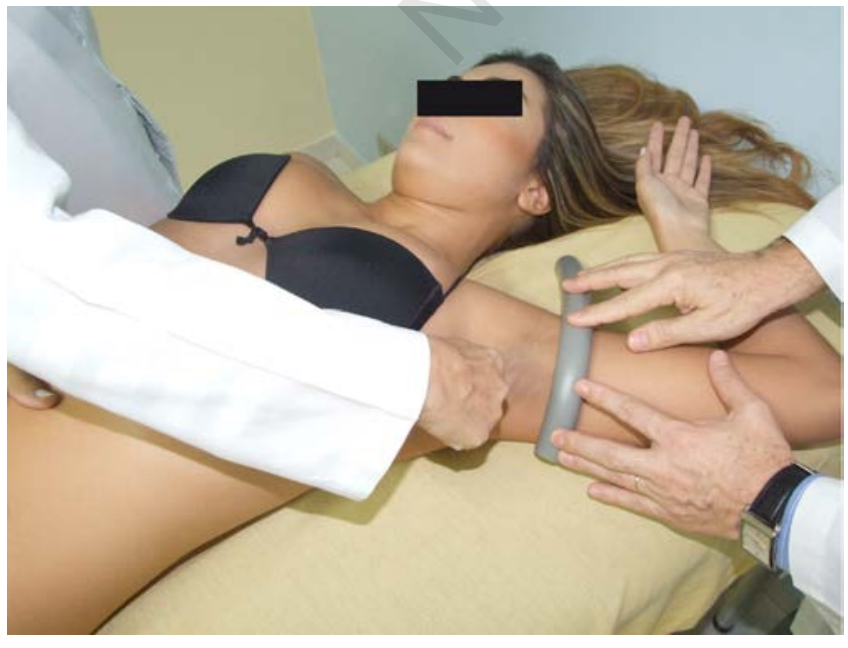

Figure 1. Manual lymphatic therapy using rollers indicated in primary lymphedema and contraindicated in secondary lymphedema.

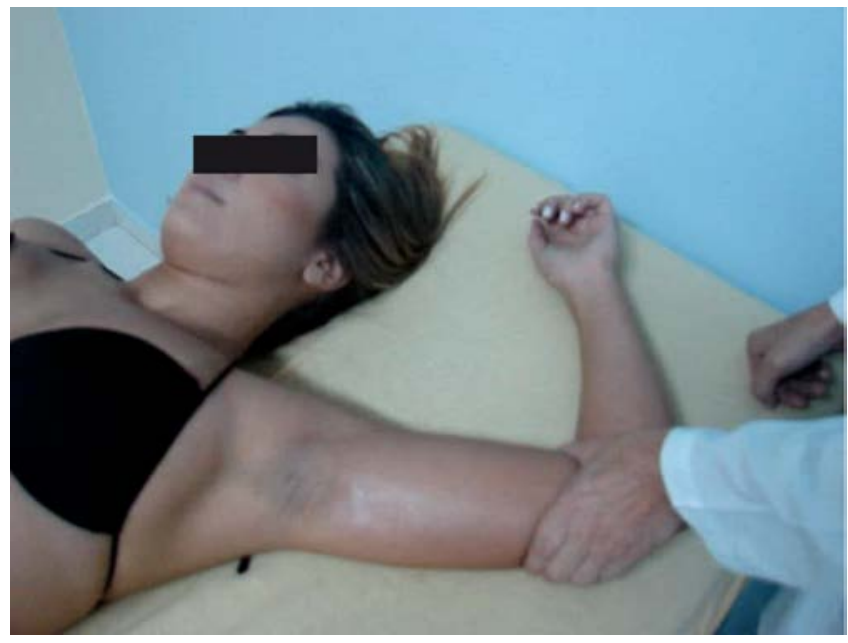

Figure 2. Manual lymphatic therapy using linear movements for primary lymphedema. 
treatment of lymphedema. ${ }^{5}$ The most important studies however, performed with nuclear medicine, showed the displacement of macromolecules with two models being used to develop and evaluate this technique. The first model performs lymphoscintigraphic scans before and after linear lymph drainage in a region of a limb, Figure 5A and B, usually the thigh (without simultaneous monitoring of images) to see the resulting movement of the radioisotope. The second model, which is more appropriate to immediately assess the effect of the movements, is, after an imaging scan, to perform linear lymph drainage with simultaneous monitoring on a computer screen.

This technique allows a visual evaluation on the computer screen of the displacement of lymph caused by the movement of the hand with documented quantitative and qualitative variations. Thus an evaluation of the effectiveness of all techniques of manual lymph drainage to mobilize macromolecules can be

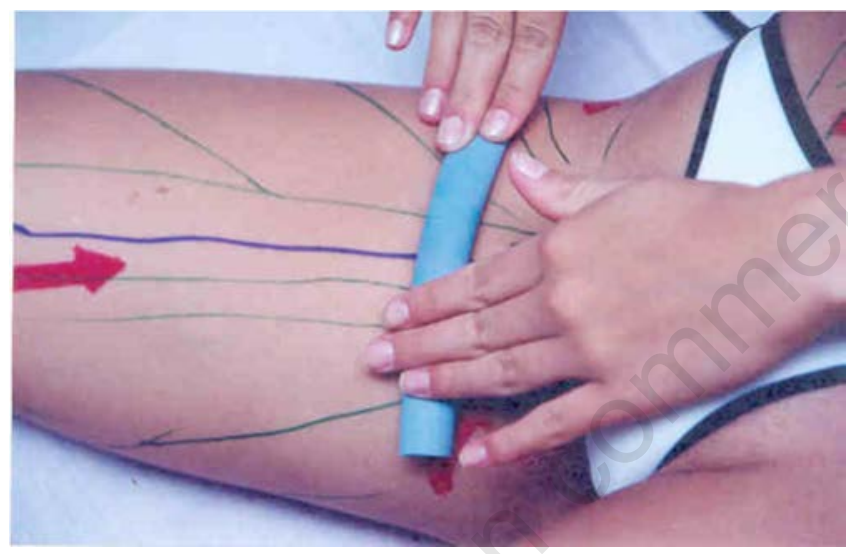

Figure 3. Auto lymphatic therapy technique using roller.

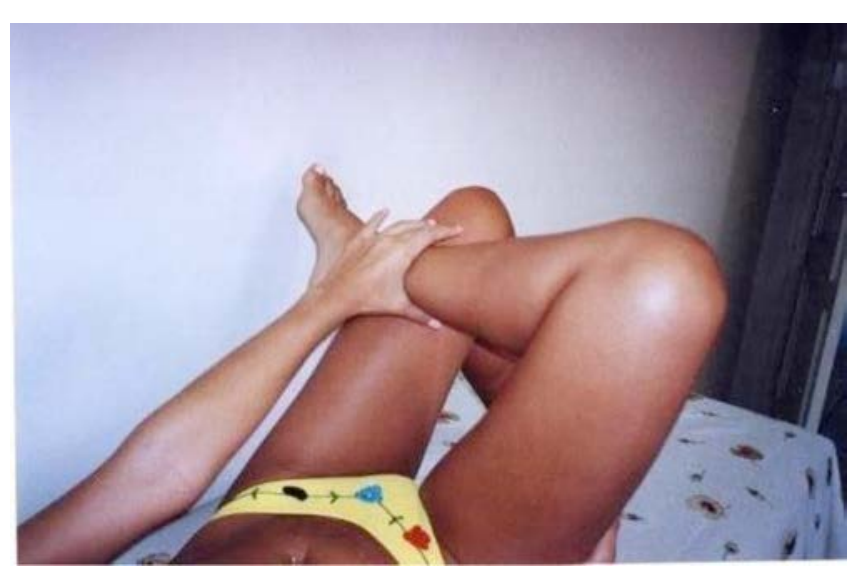

Figure 4. Auto lymphatic therapy technique using linear manual movements.

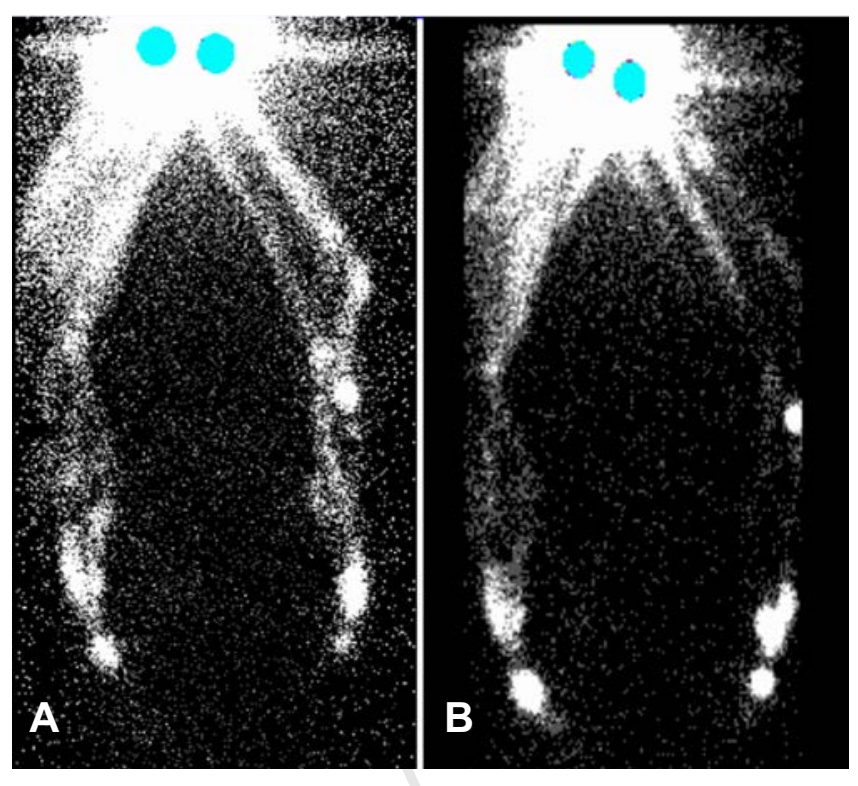

Figure 5. Lymphoscintigraphic image before (A) and after (B) a single manual passage in the limb using manual lymphatic therapy with linear movements indicated for primary lymphedema.
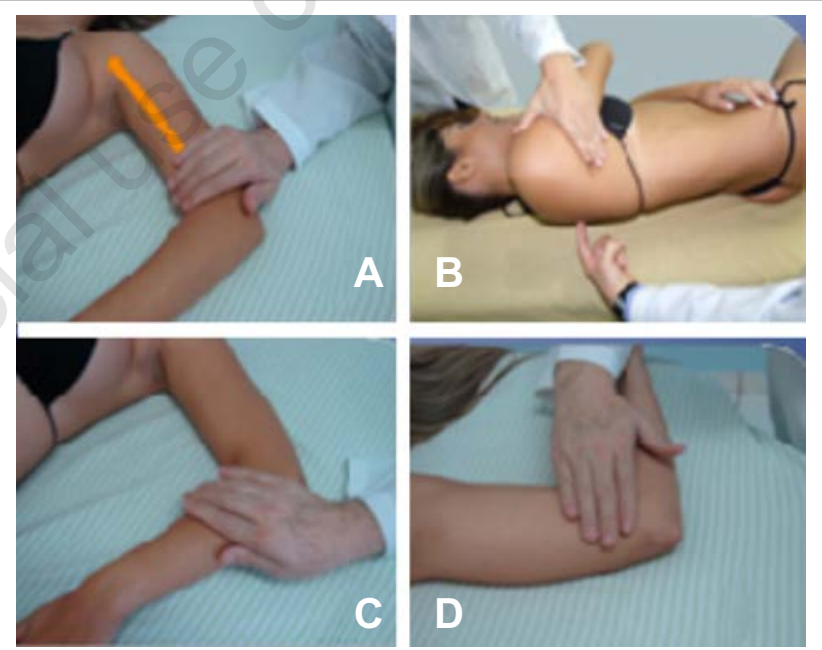

Figure 6. A-D) The adaptation of the technique with axillary lymph node resection after breast cancer, where linear movements in the cephalic and posterior (when patent) and intermittent compression therapy are performed in each limb.

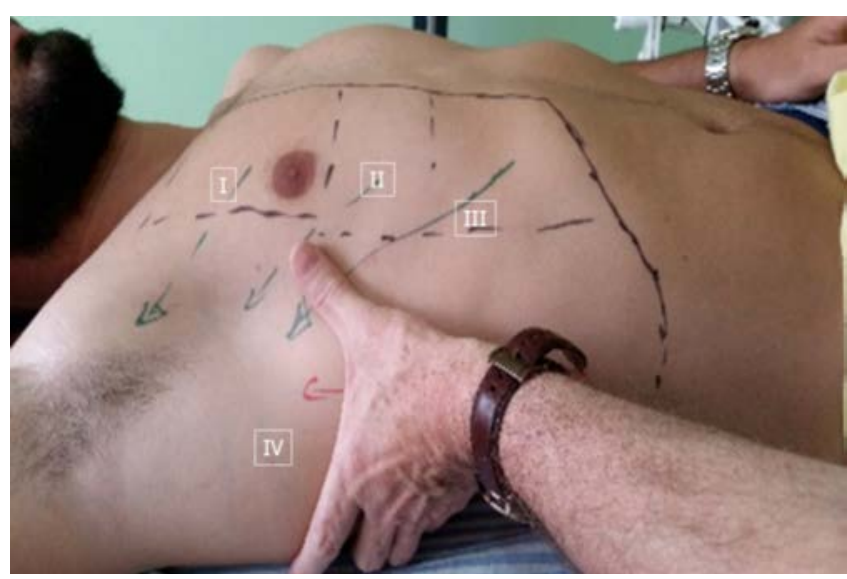

Figure 7. Schematic linear pathways to be drained in the thorax in primary lymphedema using the Godoy \& Godoy technique. 
performed. ${ }^{11,12}$ Some types of lymphedema associated with lymph node resection or with mechanical blockage of the lymphatics require an adaptation of the technique (Figures 6 and 7). This aspect has been evaluated in the most common types of cosmetic, reconstructive or oncologic surgery with adaptations being made for each pathophysiological process making these techniques safe in the preoperative recovery of both aesthetics and reconstructive surgeries. ${ }^{5}$ The best example here is breast cancer treatment-related lymphedema. In this case a specific technique for chest and arm lymphedema was developed using intermittent compression therapy (ICT).

Thus, five main variants of the drainage techniques have been described over the years: i) manual lymph drainage using rollers; ii) self-applied manual lymph drainage using rollers; iii) manual lymph drainage using the hands (manual lymphatic therapy); iv) mechanical lymphatic therapy using the RAGodoy ${ }^{\circledR}$ device; v) lymphatic therapy after breast cancer treatment using ICT.

Lymphoscintigraphic, volumetry and bioimpedance analyses were made for both arms and legs. The minimum duration of a lymphatic therapy session in order to observe a significant change in volume is one hour.

\section{Conclusions}

In brief, a continuous relentless evolution of lymphatic therapy techniques has been observed in recent years with the aim of improving the treatment of patients.

\section{References}

1. Chikly BJ. Manual techniques addressing the lymphatic system: origins and development. J Am Osteopath Assoc 2005;105:457-74.

2. Kasseroller R. Compendium of Dr. Vodder's manual lymphatic drainage. Translated David Michael Fogg. Heidelberg: Haug; 1998.

3. Godoy JMP, Godoy MFG. Drenagem Linfática Manual. Uma Nova Técnica. São Jose do Rio Preto: Lin Comunicação; 1999. pp 60.

4. Godoy JMP, Godoy MFG. Drenagem Linfática Manual. Uma Nova Abordagem. São Jose do Rio Preto: Lin Comunicação; 1999. pp 80.

5. Godoy MFG, Godoy ACP, Godoy JMP. Manual Lymphatic Therapy: The Godoy \& Godoy Concept. Translated by David Hewitt. São Jose do Rio Preto: THS, 2012.

6. de Godoy JM, Santana KR, Godoy MDeF. Lymphoscintigraphic evaluation of manual lymphatic therapy: the Godoy \& Godoy technique. Phlebology 2013 [Epub ahead of print].

7. de Godoy JM, Iozzi AJ, Azevedo WF Jr, Godoy Mde F. New method to assess manual lymph drainage using lymphoscintigraphy. Nucl Med Rev Cent East Eur 2012 27;15:140-2.

8. Soligo CG, Godoy JMP, Godoy MdFG, Taglietto VR. New technique of lym- phatic drainage improving the lymphoscintigraphic pattern in traumatic lymphedema: case report. Arq Ciênc Saúde 2008;15:43-5.

9. Pereira De Godoy JM, Franco Brigidio PA, Salles Cunha SX, et al. Mobilization of fluids in large volumetric reductions during intensive treatment of leg lymphedema. Int Angiol 2013;32:479-82.

10. Libanore D, Buzato E, Barufi S, et al. Bioimpedance assessment of edema in patients with mastectomy-related lymphedema treated by mechanical lymph drainage using the RAGodoy ${ }^{\circledR}$ device. J Phlebol Lymphol 2011;4:31-3.

11. Godoy JMF, Godoy MFG, Batigalia F. Preliminary evaluation of a new, more simplified physiotherapy technique for lymphatic drainage. Lymphology 2002;35:91-3.

12. Godoy JMP, Braile DM, Godoy MFG. A thirty-month follow-up of the use of a new technique for lymph drainage in six patients. Eur J Vasc Endovasc Surg 2002;3:91-3.

13. Godoy JMP, Godoy MFG. Manual lymph drainage: a new concept. J Vasc Br March 2004;3:77-80.

14. de Godoy JM, Torres CA, Godoy MF. Self-drainage lymphatic technique. Angiology 2001;52:573-4.

15. Pereira de Godoy JM, de Fatima Guerreiro de Godoy M. Manual lymphatic drainage and linear movement. Arq Ciênc Saúde 2014;21:69. 